\title{
IN VITRO PLANT REGENERATION FROM ALGINATE ENCAPSULATED SHOOT TIPS OF CASIMAIROA EDULIS L.
}

\author{
Abd Alhady, Mohamed Reda A. \\ Tissue Culture Unit, Department of Genetic Resources, Desert \\ Research Center, El-Matareya, Cairo, Egypt \\ E-mail: mohamedreda240@yahoo.com
}

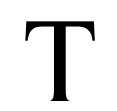

he present study aimed at developing a method for plant regeneration from alginate-encapsulated shoot tips of Casimairoa edulis. Shoot tips excised from in vitro proliferated shoots were encapsulated in calcium alginate beads. The best composition was achieved using 3\% sodium alginate and 100 $\mathrm{mM}$ calcium chloride $\left(\mathrm{CaCl}_{2} \cdot 2 \mathrm{H}_{2} \mathrm{O}\right)$. The survival and regrowth percentages of encapsulation shoot tips decreased gradually with increasing storage duration at $4^{\circ} \mathrm{C}$. Encapsulated shoot tip could be stored at low temperature $\left(4^{\circ} \mathrm{C}\right)$ up to 12 weeks with a survival and regrowth frequency of 46.67 and $40.00 \%$, respectively. Supplementing the alginate matrix with three concentrations of salicylic acid $(25,50$ and $75 \mu \mathrm{M})$ was found to have pronounced effect on the survival and regrowth percentages. The survival and regrowth percentage of encapsulated shoot tips with salicylic acid at concentrations of 25,50 and $75 \mu \mathrm{M}$ increased to 65,80 and $60 \%$, respectively after 12 weeks. The best salicylic acid effect was achieved using the concentration of $50 \mu \mathrm{M}$. The represented synthetic seed technique could be useful in large-scale propagation as well as short-term conservation, germplasm distribution and exchange of $C$. edulis.

Keywords: white sapote, encapsulation, in vitro preservation, shoot tips

White sapote (Casimiroa edulis L., Rutaceae) also known as matasano and zapote is a fruit native to central America and Mexico (Yahia, 2005). This species has the following characteristics: the plant can reach 15 $\mathrm{m}$ when propagated by seeds; fruit 4 to $10 \mathrm{~cm}$ in diameter; each with white seeds, $2.5-5.0 \mathrm{~cm}$ long and $1.25-2.5 \mathrm{~cm}$ thick; the harvest time is indicated by changes in color from green to yellow (Donadio et al.,1998). White sapote is commonly propagated by seed but vegetative methods are used as grafting in California and Florida in midsummer and air layering in New Zealand (Morton, 1997). In Egypt, the white sapote trees are derived from 
seed, resulting in great genetic and fruiting variation amongst trees. Selection superior clones from outstanding seedling progeny from these seedling fruit trees are considered one of the most important methods for improving sapote cultivars. The medicinal value of sapote plant is the fruit that is consumed in many parts of the world, it was first discovered by Aztecs. The crude plant extracts of the seeds or leaves were later found to affect blood pressure (Garcia-Gonzalez et al., 1994), cardiac activity, aortic muscular tonic and to possess anticonvulsant activity (Navarro et al., 1995). Zapotin, a polymethoxylated flavonoid isolated from zapote blonco seeds has been found to be a non-toxic induces of cellular differentiation with promyelocytic cells (Navarro et al., 1995). Zapotin therefore has the potential to inhibit carcinogenesis.

Recent advances in plant biotechnology have made the synthesis of artificial seeds a reality. The artificial seed is an encapsulated somatic embryo, sown and germinated in the same manner as the conventional seed. Due to the low success and high cost of somatic embryo production, buds, shoots, bulbs or other meristematic tissue that can produce a whole plant may also be encapsulated, which are also considered as "artificial seeds" (Ahmad and Anis, 2010). The encapsulation technology, initially developed for clonal propagation through the production of synthetic seeds with somatic embryos, is currently proposed for use with non-embryogenic explants, such as buds and nodal segments (unipolar propagules) (Carla et al., 2017). Synthetic seeds technology offers an efficient means for mass propagation of plant species irrespective of the season, space, environmental factor and other hindering conditions. Furthermore, encapsulated shoot tips can be used as means to reduce the need for sub culturing during cold storage, since they require no transfer to fresh medium (West et al., 2006). Cold storage is possible to reduce the cost of maintaining germplasm cultures because it reduces the manual labor as a result of the less frequent subculturing. It also lessens the possibility of genetic instability from frequent subculturing and adventitious regeneration (West et al., 2006 and Carla et al., 2017). Encapsulation of vegetative propagules (axillary buds, shoot tips, nodal segments etc.) has become a potentially cost effective clonal propagation system and can be used as an alternative to synthetic seeds derived from somatic embryos (Sarkar and Naik, 1997 and Chand and Singh, 2004). In addition, these encapsulated vegetative propagules can also be used for germplasm conservation of elite plant species and exchange of axenic plant materials between laboratories and pharmaceutical industries (Hasan and Takagi, 1995 and Rai et al., 2009). Successful cases of synthetic seed production and plantlet regeneration have been reported for a wide range of plants including cereals, vegetables, fruits, ornamentals, medicinal plants and forest trees (Redenbaugh et al., 1991; Castillo et al., 1998; Ara et al., 2000; Mandal et al., 2000; Singh et al., 2006; Muthu et al., 2012 and Hegazi, 2016). Among with the several non-embryogenic propagules, shoot 
tip explants are more response than other explants because of the greater mitotic activity in the meristem (Ballester et al., 1997). Salicylic acid (SA) has been found to play a role during the plant response to a biotic stresses such as drought, chilling, heavy metal toxicity, heat and osmotic stress (Janda et al., 2007). It is an important signal molecule in plant defense after pathogen attack as well (Shah and Klassig, 1999). To the best of our knowledge, there has been no report on synthetic seed production using shoot tip explants on white sapote (Casimiroa edulis). In the present paper, the first attempt of the encapsulation of shoot tips of $C$. edulis in sodium alginate beads is reported. Effects were also made to test the ability of the encapsulated shoot tips to retain viability following storage at low temperature $\left(4^{\circ} \mathrm{C}\right)$ for different durations.

\section{MATERIALS AND METHODS}

\section{Plant Material}

Juvenile shoots were collected from a mature tree of Casimiroa edulis growing at Faculty of Agriculture, Al-Azhar University, Nasr City, Cairo, Egypt. Culture was established using shoot tips, then produced axillary shoots that were multiplied, following the procedure described in the earlier work of Abd Elmeged et al. (2015).

\section{Encapsulation of Shoot Tips and Storage Conditions}

Different concentrations $(1,2,3,4$ and $5 \%)$ of Na-alginate were prepared. For complexation, $100 \mathrm{mM}$ of calcium chloride $\left(\mathrm{CaCl}_{2} \cdot 2 \mathrm{H}_{2} \mathrm{O}\right)$ solution was prepared in Murashige and Skoog (1962) (MS) liquid medium. Both Na-alginate and $\mathrm{CaCl}_{2} \cdot 2 \mathrm{H}_{2} \mathrm{O}$ solutions were autoclaved at $121^{\circ} \mathrm{C}$ for 20 min after adjusting the $\mathrm{pH}$ to 5.7-5.8. Encapsulation was accomplished by mixing the shoot tips (about 3-4 mm long) into Na-alginate solution, in order to allow the explants to be covered by the gel. The alginate-covered shoot tips were then dropped in the $\mathrm{CaCl}_{2} \cdot 2 \mathrm{H}_{2} \mathrm{O}$ solution. The droplets containing one shoot tip were held for at least $30 \mathrm{~min}$ to achieve polymerization of the sodium alginate. After $30 \mathrm{~min}$, alginate beads were collected and rinsed three times with sterilized distilled water to remove the traces of $\mathrm{CaCl}_{2} \cdot 2 \mathrm{H}_{2} \mathrm{O}$. The capsules had an average diameter of 4-5 mm (Fig. 1a), and could be easily handled under sterile conditions, preventing dehydration of the explants. Encapsulated shoot tips were stored for 1, 2, 4, 6 and 8 weeks at $4^{\circ} \mathrm{C}$ (in the dark) on water agar medium $(0.7 \% \mathrm{w} / \mathrm{v}$ agar $)$. Non-encapsulated shoot tips were treated as control.

\section{Plant Regeneration}

Encapsulated shoot tips were cultured on plant growth regulatorsfree MS medium for the recovery of plantlets. After six weeks, viability, growth and the average shoot length $(\mathrm{cm})$ were recorded. The capsules were 
considered alive if the shoot tips were still green, with no necrosis or yellowing. Regrowth percentage was evaluated as percentage of capsules that had shown any visual growth activity, and increase in size, with breakage of the capsule and extrusion of at least a small shoot.

\section{Effect of Salicylic Acid on Survival and Regrowth Percentages of Encapsulated Shoot Tips}

The best complexation of alginate matrix was supplemented with three different concentrations of SA $(25,50$ and $75 \mu \mathrm{M})$, in addition to the control treatment without SA. Encapsulated shoot tips of Casimiroa edulis were cultured on plant growth regulators free MS medium and survival and growth percentages were evaluated after 12 weeks of storage at low temperature $\left(4^{\circ} \mathrm{C}\right)$.

\section{Rooting and Acclimatization}

For rooting, shoots about 4-5 cm long were excised and transferred to MS medium containing $2.0 \mathrm{mg} / \mathrm{L}$ 3-Indol butyric acid (IBA). After rooting, regenerated plantlets were washed carefully to remove residual agar and planted in plastic pots containing a mixture of sand and peat (1:1) moistened with tap water. Plantlets were covered with polyethylene bag to maintain high humidity. After a month, surviving plants were transferred to pots containing normal gradual soil and maintained in greenhouse.

\section{RESULTS AND DISCUSSION}

\section{Effect of Sodium Alginate Concentration on Conversion of Encapsulated Shoot Tips}

Sodium alginate and calcium chloride had an important role in gel matrix formation, gel complexation and capsule hardiness, which depend on the optimal ion exchange of $\mathrm{Na}$ and $\mathrm{Ca}^{2+}$ (Singh et al., 2006). The encapsulated beads differed morphologically with respect to texture, shape and transparency, with different combinations of Na-alginate $(2,3$ and $4 \%$ and $\mathrm{CaCl}_{2} \cdot 2 \mathrm{H}_{2} \mathrm{O}(100 \mathrm{mM})$. The assessment of the effect of various concentrations of $\mathrm{Na}$-alginate and calcium chloride was prerequisite in order to standardize the preparation of beads. An encapsulation matrix of $3 \% \mathrm{Na}$ alginate with $100 \mathrm{mM}$ of $\mathrm{Ca} \mathrm{Cl}_{2} \cdot 2 \mathrm{H}_{2} \mathrm{O}$ was found the most suitable for the formation of ideal beads. Lower concentration of sodium alginate $(2 \%)$ became unsuitable for encapsulation because the resulting beads were without a defined shape and too soft to handle, perhaps because of a reduction in its gelling ability following exposure to high temperature during autoclaving. At higher concentration of Na-alginate (4\%), the beads were diametric, hard and caused considerable delay in regeneration. This result was also observed by Larkin et al. (1988) and Pattnaik et al. (1995). The data in table (1) show that the gelling matrix of 3\% Na-alginate and $100 \mathrm{mM}$ $\mathrm{CaCl}_{2} \cdot 2 \mathrm{H}_{2} \mathrm{O}$ gave the highest survival and regrowth percentage of 73.33 and 
$91.9 \%$, respectively, compared with the gelling matrix of $4 \%$ Na-alginate, which gave the lowest survival and regrowth values (46.66 and 57.14\%, respectively) (Fig. 1b). This different response may be due to a synergetic effect of Na-alginate and calcium chloride. Hence 3\% Na-alginate and 100 $\mathrm{mM} \mathrm{CaCl} 2.2 \mathrm{H}_{2} \mathrm{O}$ chloride was used for the encapsulation of shoot tips of Casimiroa edulis in the further experiments. The results were similar to the findings of Faisal et al. (2006) working on Rauvolfia tetraphylla, Naik and Chand (2006) working on Punica granatum, Singh et al. (2006) working on Phyllanthis amarus, Hegazi (2011) working on Capparis orientalis and Vivek et al. (2016) working on Manihot esculenta.

Table (1). Effect of sodium alginate concentration on survival and regrowth percentages of Casimiroa edulis encapsulated shoot tips.

\begin{tabular}{ccc}
\hline $\begin{array}{c}\text { Sodium alginate } \\
\text { concentration }(\boldsymbol{\%})\end{array}$ & $\begin{array}{c}\text { Survival } \\
(\boldsymbol{\%})\end{array}$ & $\begin{array}{c}\text { Regrowth (\%) to } \\
\text { survival }\end{array}$ \\
\hline 2 & 60.00 & 77.77 \\
3 & 73.33 & 91.90 \\
4 & 46.66 & 57.14 \\
5 & 40.00 & 43.00 \\
\hline
\end{tabular}

\section{Effect of Different Storage Durations on Conversion of Encapsulated Shoot Tips}

A desirable feature of the encapsulation is the ability to retain survival and regrowth potential even after storage. High humidity and low temperature were essential conditions for retention of viability and thus for storage of encapsulated shoot tips. Percentage of regrowth and conversion of encapsulated shoot tips decreased gradually with increasing storage duration at $4^{\circ} \mathrm{C}$ (Table 2). Similarly, the conversion frequency of encapsulated shoot tips of Phyllanthus amarus also declined markedly following storage at low temperature (Singh et al., 2006). After storage for 12 weeks, the percentage of survival and regrowth to survival of encapsulated shoot tips were 46.66 and $40.00 \%$, respectively. Whereas the percentage of survival and regrowth was $100 \%$ for both of them before storage. It is assumed that the decline in the conversion of encapsulated propagules stored at low temperatures may be due to the inhibited respiration of plant tissues because of the alginate cover (Naik and Chand, 2006 and Micheli et al., 2017). Also, Redenbaugh et al. (1991) reported that the decline in plant recovery of stored encapsulated vegetative propagules may be due to both oxygen deficiency in the calcium alginate bead and its rapid drying. Bazinet et al. (1992) found in Daucus carota that plant regeneration rate after storage was reduced by loss of viability caused by mechanical constraints of diffusional limitation. However, the decline in morphogenesis could be attributed to an inhibited respiration of the tissues by the alginate matrix or a loss of moisture due to partial desiccation, which was observed during storage. It is not known 
whether the explants tissue or the alginate matrix caused this moisture loss (Danso and Ford-Lloyd, 2003; Hegazi, 2016 and Vivek et al., 2016).

Table (2). Effect of different storage durations on survival and regrowth percentages of encapsulated shoot tips of Casimiroa edulis.

\begin{tabular}{ccc}
\hline Duration (weeks) & Survival (\%) & $\begin{array}{c}\text { Regrowth (\%) to } \\
\text { survival }\end{array}$ \\
\hline 0 & 100.00 & 100.00 \\
2 & 93.33 & 92.85 \\
4 & 80.00 & 83.33 \\
8 & 60.00 & 66.66 \\
12 & 46.66 & 40.00 \\
\hline
\end{tabular}

\section{Effect of Salicylic Acid in the Alginate Matrix on Conversion of Encapsulated Shoot Tips}

The in vitro survival and regrowth of the capsules were analyzed to evaluate the effect of SA at $0,25,50$ and $75 \mu \mathrm{M}$ (Table 3). After 12 weeks, SA free alginate matrix gave the least survival and regrowth percentages, which were 46.7 and $40 \%$, respectively. Salicylic acid proved to be significantly effective on survival of encapsulated shoot tips with 65,80 and $60 \%$ for 25,50 and $75 \mu \mathrm{M}$, respectively. While, regrowth to survival percentage was $62.0,90$ and $60 \%$, respectively (Table 3 ). The results show that SA plays a crucial role in the resistance of these tissues to cold storage. Salicylic acid is a natural substance, which is often associated with a role in plant responses to physical and biological aggressions (Raskin, 1992 and Bernard et al., 2002). Most papers, on this subject, have reported the protective effect of exogenous SA against a biotic stress such as low temperature (Janda et al., 2007 and Katouzi et al., 2011). The current study puts an apparent role on display in shoot tips submitted to the stress of cold storage. Exogenous application of SA may lead to an enhancement of endogenous SA (Seo et al., 1995), which may also play an active role, in the process of resistance to desiccation and low temperature (Bernard et al., 2002). Endogenous SA is an induction signal for specific defense responses of plants (Shah and Klassig, 1999) and it has been shown that it acts by causing water stress in the tissues and it is also very high in the cold (Bernard et al., 2002). It is worth mentioning that water stress is also very high in cold preservation since it is enhanced by the conditions of experimentation with the storage of encapsulated shoot tips in empty Petri dishes without water support. The presence of SA in the medium of encapsulation matrix in the current study and the significant increase in the percentage of viability of shoot tips within the conditions of storage may offer a better explanation of its effect on the water stress and cold 
preservation. The successfully converted shoot tips were multiplied then transferred to be rooted and acclimatized (Fig. 1d-f).

Table (3). Effect of salicylic acid in the alginate matrix on the survival and regrowth percentages of encapsulated shoot tips of Casiniroa edulis after 12 weeks.

\begin{tabular}{ccc}
\hline $\begin{array}{c}\text { Salicylic acid } \\
\text { treatment }(\boldsymbol{\mu M})\end{array}$ & Survival $(\%)$ & $\begin{array}{c}\text { Regrowth (\%) to } \\
\text { survival }\end{array}$ \\
\hline 0 & 46.7 & 40 \\
25 & 65.0 & 62 \\
50 & 80.0 & 90 \\
75 & 60.0 & 60 \\
\hline
\end{tabular}
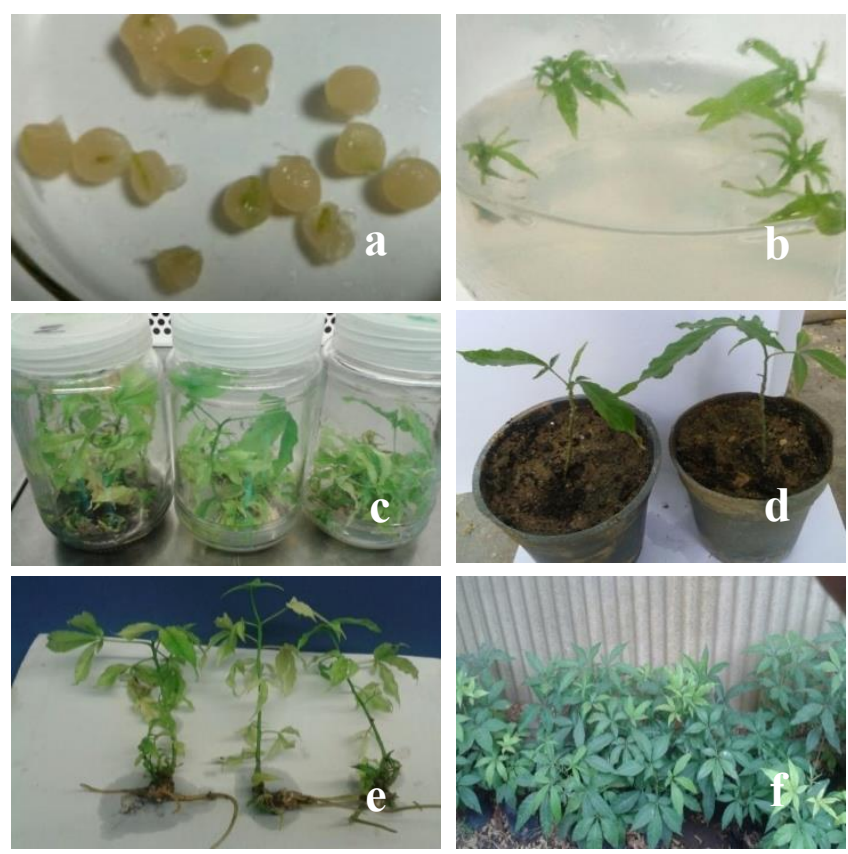

Fig. (1). a. Encapsulated shoot tips of Casiniroa edulis. b-f. Regeneration of encapsulated shoot tips of Casiniroa edulis followed by multiplication, rooting and acclimatization inside then outside the greenhouse.

\section{CONCLUSION}

The present protocol provides a promising and cost-effective method for a large-scale propagation of this important fruit. The addition of SA in the encapsulation matrix possibly reinforces the tolerance of the tissues to the cold storage. Successful plant regeneration from encapsulated shoot tips 
storage at low temperature $\left(4^{\circ} \mathrm{C}\right)$ indicates that the method described in this article can be potentially used to preserve the germplasm of Casimiroa edulis over a short period. This can also facilitate the transport of encapsulated shoot tips to laboratories of distant places for large-scale application of process. However, further experiments are needed to activate a higher percentage of conversion after the storage of encapsulated shoot tips of Casimiroa edulis.

\section{REFERENCES}

Abd Elmeged, M.R., R.E. Abo Elfadl and S.A. Hassanen (2015). Propagation of Sapota Casimiroa edulis trees by using tissue culture technique. Egyptian J. Desert Res., 65 (2): 233-242.

Ahmad, N. and A. Anis (2010). Direct plant regeneration from encapsulated nodal segments of Vitex negundo. Biol. Plantarum, 54 (4): 748-752.

Ara, H., U. Jaiswal and V.S. Jaiswal (2000). Synthetic seed: prospect and liminations. Current Sci., 78: 1438-1444.

Ballester, A., L.V. Janerio and A.M.Vieitez (1997). Storage of shoot culture and alginate encapsulation of shoot tips of Camellia japonica and $C$. retculata Lindly. Scientia Hort., 71: 67-78.

Bazinet, C., A. Kersuler, V. Dufrene, R. Timer, J.F. Mervagauli, and J.N. Barbotin (1992). Physiological somatic embryos (Ducus carota L.) behavior depending on the storage conditions. Biotechnology, 92: 139.

Bernard, F., H. Shaker-Bazarnov and B. Kaviani (2002). Effects of salicylic acid on cold presser-vation and cryopreservation encapsulation embryonic axes of Persian lilac (Melia azaderacht L.). Euphtica, 123: 85-88.

Carla, B., M. Maurizio and A. De Carlo (2017). An improved encapsulation protocol for regrowth and conservation of four ornamental species. Acta Soc. Bot. Pol., 86: 1-12.

Castillo, B., M.A.L. Smith and U.L.Yadav (1998). Plant regeneration from encapsulated nodal somatic embryos of Carica papaya L. Plant Cell Rep., 17: 172-176.

Chand, S. and A.K. Singh (2004). Plant regeneration from encapsulated nodal segments of Dalbergia sissoo Roxb. - A timber-yielding leguminous tree. J. Plant Physiol., 161: 237-243.

Danso, K.E. and B.V. Ford-Lloyd (2003). Encapsulation of nodal cuttings and shoot tips for storage and exchange of cassava germplasm. Plant Cell Report, 21: 718-725.

Donadio, L.C., J.C. Nachtigal and C.K. Sacramento (1998). In "Fruits Exoticas". Edufal, Maceio, 279 pp. 
Faisal, M., N. Ahmad and M. Anis (2006). In vitro plant regeneration from alginate-encapsulated microcutlings of Rauvolfia tetraphyla L. World J. Agr. Sci., 1: 1-6.

Garcia-Gonzalez, M., B.E. Freer and M.O. Morales (1994). Effects of Cosimiroa edulis (Rutaceae) on blood pressure heart rate in Albino rats. Rev. Biol. Trop., 42: 115-119.

Hasan, S.M.Z. and H. Takagi (1995). Alginate-coated nodal segments of yam (Dioscoria spp.) for germplasm exchange and distribution. Plant Genetic Resources News Letter, 103: 32-35.

Hegazi, Gh.A. (2011). Viability of encapsulated shoot tips of Capparis orientalis Duh. Nature and Science, 9 (8): 223-228.

Hegazi, Gh.A. (2016). In vitro preservation of Bacopa monnieri (L.) Pennell as a rare medicinal plant in Egypt. Journal of Basic and Applied Scientific Research, 6 (12): 35-43.

Janda, T., E. Horvath, Szalai and E. Paldi (2007). In "Role of Salicylic Acid in the Induction of Abiotic Stress Tolerance". (Hayat, S. and A. Ahmed Eds.). Salicylic acid A Plant Hormone, Springer, p. 91-150.

Katouzi, S.S.S., A. Majd, F. Fallahian and F. Bernard (2011). Encapsulation of shoot tips in alginate beads containing salicylic acid for cold preservation and plant regeneration in sunflower (Helianthus annus L.). Austratian J. Crop Science, 5 (11): 1469-1474.

Larkin, P.J., P.A. Davis and G.J. Tanner (1988). Nurse culture of low number of Medicago and Nicotiana protoplast using calcium alginate beads. Plant Science, 58: 203-210.

Mandal, J., S. Pattanik and P.K. Chand (2000). Alginate encapsulation axillary buds of Ocinum americonum L. (hoary basil). $O$. basillicum L. (Sweet basil), O.gratissimum L. (sharuby basil) and $O$. sanctum (Sacred basil). In vitro Cell Dev. Biol. Plant, 36: 287-292.

Micheli, M., Bececco, T. Gardi, L. Martorana, B. Chincone and M.A. Germana (2017). Encapsulation of black mulberry microcuttings: studies on capsules and synthetic seeds. Acta Hortic., 11: 55.

Morton, J. (1997). In "Whit Sapota". (Morton, J. Ed.). Fruits of Warm Climates, University of Florida, Miami, USA, p. 191-196.

Murashige, T. and F. Skoog (1962). A revised medium for rapid growth and bioassays with tobacco tissue culture. Plant Physiol., 15: 473-497.

Muthu, T., P. Naglla and C. Min (2012). Plant regeneration from alginateencapsulated shoot tips of Momordica dioica for short term storage and germplasm exchange and distribution. Dmies Journal Po., 5 (3): 266-270.

Naik, S.K. and P.K. Chand (2006). Nutrient-alginate encapsulated of in vitro nodal segments of pomegranate (Punica granatum L.) for germplasm distribution and exchange. Scienta Horticulturae (Amsterdam), 108: 247-252. 
Navarro, R.A., R.B.E. Bastidas, F.J. Garcia, L.P. Garcia and P. Garzon (1995). Anticonvulsant activity of Casimiroa edulis in comparision to phextion and phenobarbital. J. Ethnopharmacol, 45: 199-206.

Pattnaik, S.K., Y. Sahoo, P.K. Chand (1995). Efficient plant retrieval from alginqte-encapsulated vegetative buds of mature mulberry trees. Scienta Horticulturae (Amsterdam), 61: 227-239.

Rai, M.K., V.S. Jaiswal and U. Jaiswal (2009). The encapsulation technology in fruit plants a review. Biotech Advances, 27: 671-679.

Raskin, I. (1992). Role of salicylic acid in plants. Ann. Rev. Plant Physiol., 43: 439-463.

Redenbaugh, J.A., Fujii, D. Slade, P.R. Visa and M.E. Kossler (1991). In "Artificial Seeds Encapsulated Embryos. (Bajaj, Y.P.S. Ed.). Biotechnology in Agriculture and Forestry: High Technology and Micropropagation. 17 Heidelberg Springer Verlag, Berlin, p. 395-416.

Sarkar, D. and P.S. Naik (1997). Synseeds in potato an investigation using nutrient encapsulated in vitro nodal cutting segments. Scientia Hort., 73: 179-184.

Seo, S., Ishizuka and Y. Ohashi (1995). Induction of salicylic acid betaglucosidase in tobacco leaves by exogenous salicylic acid. Plant Cell Physiol., 36 (3): 447-453.

Shah, J. and D.F. Klassig (1999). In "Salicylic Acid Signal Perception and Transduction". (Hooykass, P.H., M.A. Hall and K.R. Libbenge Eds.) Biochemistry and Molecular Biology of Plant Hormones. Elsevier Science, p. 513-541.

Singh, A.K., M. Sharma, R. Varshney, S.S. Agarwal and K.C. Bansal (2006). Plant regeneration from alginate-encapsulated shoot tips of Phyllanthus amarus Schum and Tonn, a medicinally important plant species. In vitro Cell Dev. Biol. Plant, 42: 109-113.

Vivek, H., T. Makeshkumar, M.N. Sheela, C.V. Chandra, A.V.V. Koundinya, S.R. Anil, R. Muthuraj and S. Darshan (2016). Production of synthetic seed in cassava (Manihot esculenta Crantz). Journal of Root Crops, 42 (2): 5-9.

West, T.P., M.B. Ravindra and J.E. Preece (2006). Encapsulation, cold storage, and growth of Hibiscus moscheutos nodal segments. Plant Cell Tiss. Org. Cul., 87 (3): 223-231.

Yahia, E. M. (2005). In "Sapodila and Related Fruits". Universidad Autome de Queretano, Mexico, 6 pp. 


\section{تجديد نمو القمم النامية المكبسلة معمليًا لنبات السابوتا}

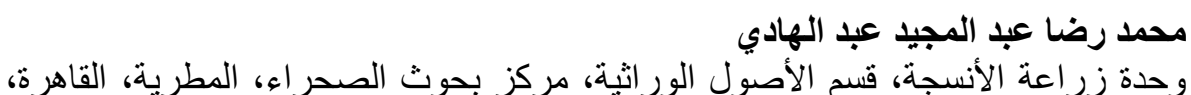

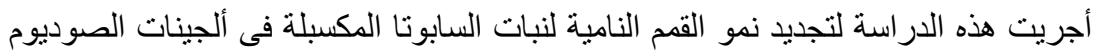

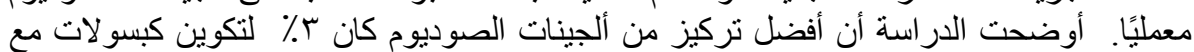

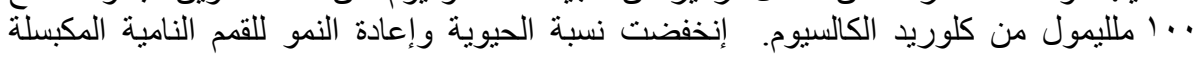

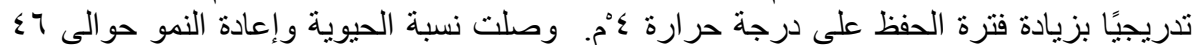

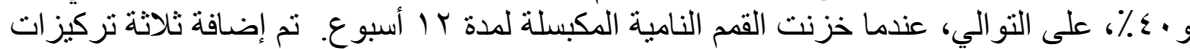

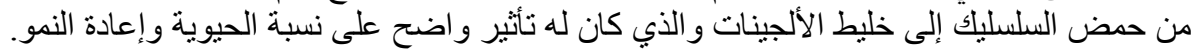

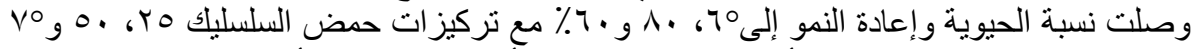

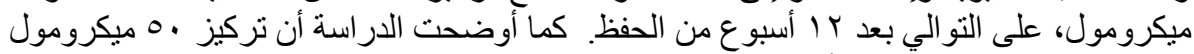

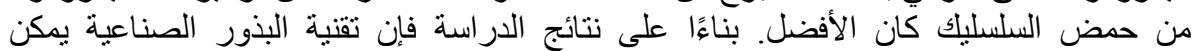
أستخدامها في نبات السبوتا بنجاح على نطاق واسع. 